\title{
Height Evaluation and Linear Accuracy of Digital Level, Total station, GPS and Orthophoto
}

\author{
Abdulrahman F. Heetoํㅓㄴ Yousif Y. Zaia², Sami M. Gilyane ${ }^{3}$ \\ Department of Surveying Engineering, University of Duhok, Kurdistan Region - Iraq
}

\section{ABSTRACT}

In this research, Digital level (DL), Total station (TS) and GPS were used to assess accuracy and precision of the height component. Field observations were implemented in two tested areas. A reference network which consisted of 34 points on area1 and 10 control points on area 2 which had been observed five times using Digital level, RTK-GPS and Total station (TS) where Digital level was considered as a base for comparison. Several known control points were used as check points to evaluate the accuracy of measurements. According to the obtained results, TS and GPSRTK measurements were compared with the adjusted reference points measured by precise Digital level (DNA 03). Around $\pm 15 \mathrm{~mm}$ standard deviation for TS and $\pm 13.5 \mathrm{~mm}$ for GPS were achieved. Linear accuracy of TS, GPS, and orthophotos measurements from Vossing German Company were also investigated in regular features within the same tested areas. The actual lengths were measured with steel tape up to a millimeter accuracy and were considered as being a base for comparing. The maximum deviation $22 \mathrm{~mm}$ accuracy has been obtained in area 2 and $12 \mathrm{~mm}$ in area1. The study shows that the extracted features from orthophotos had less accuracy in hilly regions due to relief displacement whereas they were more accurate in gentle slopes.

KEYWORDS : Digital level, Total station and DGPS, Orthophoto, Linear accuracy, Analysis and Comparison.

\section{INTRODUCTION}

Surveying has been an important factor in the development of the human environment for many centuries. It is a prerequisite requirement in the planning and implementation of nearly every form of construction. The significant development of surveying methods have added flexibility in data and information collection and enabled potentially a wider range of applications. Moreover, surveying techniques played a significant role in the progress of $3 \mathrm{D}$ coordinates of the point of interest whereby increasing its application. In many applications, the role of surveying has been intended to be used for better accuracy. The term accuracy is common in several applications to express the quality of observations, measurements and computations. Sjöberg (2012), explained that the

Academic Journal of Nawroz University

(AJNU) Volume 7, No 4 (2018).

Regular research paper : Published 8 December 2018

Corresponding author's e-mail : farsat.heeto@uod.ac

Copyright @2017 Abdulrahman F. Heeto', Yousif Y. Zaia²,

Sami M. Gilyane 3

This is an open access article distributed under the Creative Commons Attribution License. required accuracy depends on the need of achieving production which were divided into three categories such as low, medium and high accuracies. Low accuracy includes common navigation works on the sea, position and velocity in small scale geophysical exploration. Medium accuracy contains navigation in coastal waters, earthquake survey and hydrographic survey. The applications that require high accuracy are engineering construction projects, precise continuous height control, deformation monitoring and precise hydrographic surveying and etc. The accuracy of surveying methods used in this research, GPS, TS, Digital level, and aerial photos depend on a number of elements that limit the quality of measured data. For example: GPS positioning errors include satellite position, satellite clock, and receiver clock, signal delay due to troposphere and ionosphere, and multipath error as well as the limitations of receiver hardware and software (Amin, 2004). Regarding the limitations from the total station (TS), the accuracy of measuring data is affected by distance limit, the shorter the distance the better the accuracy that can be achieved. Whereas the accuracy of digital level depends on the orthogonally of the barcode rods over the point of interest and the distance from the rod to the instrument. Finally, 
accuracy of aerial photos depend on the field of view, altitude and etc. i.e. images taken from nadir (vertical photos) is more accurate than oblique images. The accuracy of survey instruments have been investigated and assessed by many researchers. In the work of Lin (2004) the accuracy of GPS-RTK and total stations were tested. The results indicated that the positional accuracy of GPS-RTK was better than the TS, about $1.4 \mathrm{~cm}$ achieved when the GPS-RTK was used and the possibility of $1.6 \mathrm{~cm}$ was determined when TS was used. Ehsani et al. (2004), tested a 0.5 square kilometer area with RTK-GPS, the base station and four reference points that had been established in the highest point of the selected area. Corrections for GPS signals were received in real time from a base receiver at a known position to all rover receivers' points. The results of their work show that a horizontal position accuracy of 1 $\mathrm{cm}$ was achieved by compensating for atmospheric delay (Ionosphere and troposphere), and other variable errors in GPS geometry. In contrast to GPS, TS can give better results in urban areas, due to the obstruction of satellite visibility such as urban canyon, tree canopy and tall buildings. These obstructions degrade the signal of GPS in those urban areas. In such cases TS are used, this was clearly shown in Borgelt S C. et al. (1996). They reported that the accuracy of TS compared with RTK-GPS in open sky can give standard deviation about of $0.12 \mathrm{~m}$ in vertical position. While in obstructed areas, better accuracy was obtained using TS, which was below $0.5 \mathrm{~cm}$. Two areas, with good and poor GPS visibility were selected for assessing the quality of RTK. The result showed that the quality of RTK-GPS with good GPS visibility were better than obstructed areas (Abdulrahman, 2013). Accuracy of different RTK-GPS instruments such as Leica, Topcon and Trimble, were tested on nine control points by Jonsson K.O. et al. (2003), total station was also applied on the same points. The results achieved from GPS-RTK measurements in a horizontal and vertical components were $(0.1$ and 2$) \mathrm{cm}$ respectively. The work conducted by Ahmed (2012), GPS-RTK with TS measurements were tested on a network implemented in the campus of Royal Institute of Technology (KTH), School of Architecture and the

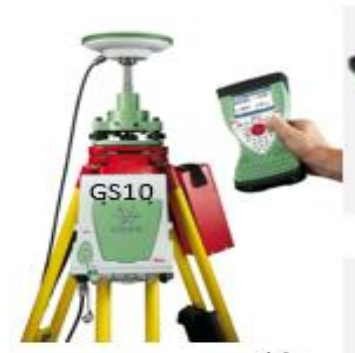

(a)
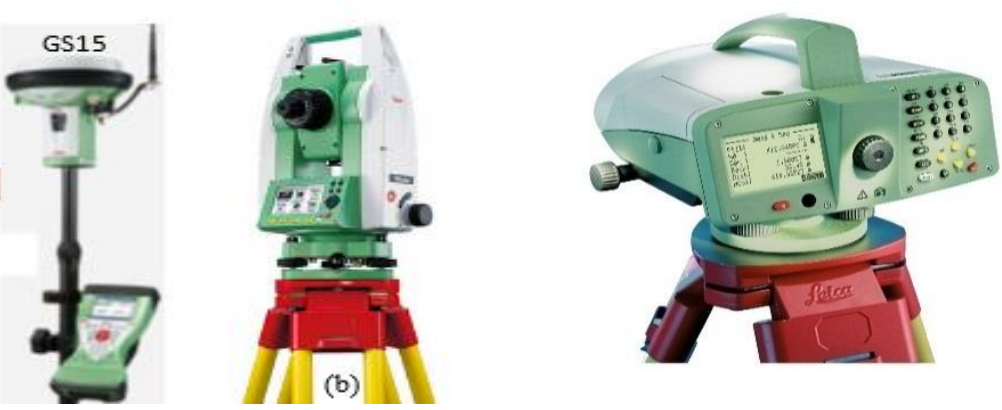

Built Environment, Stockholm, Sweden. The objective was to assess the RTK-GPS achievable accuracy, which tested the standard deviation of the observations under different satellites configurations and evaluated RTKGPS achievements in urban areas. The test showed that the assessment of accuracy and precision of the RTKGPS was accomplished by comparing the coordinates of the observed points with that of separately accurate ones using TS. The result indicated that the difference between the coordinates of the total station and RTKGPS were found to be (2 and 3) $\mathrm{cm}$ for the horizontal and vertical coordinates respectively. While the results conducted by Chekole. (2014) on the same tested area were $1.8 \mathrm{~cm}$ for both horizontal and vertical coordinates. To sum up the aforementioned works, the limitation of GPS, TS and Digital level also have different time consumption in the field works. Therefore, the aim of this paper is to assess and compare precision and accuracy of the above survey techniques. The objective of this study is to focus on collecting data from field measurements using different surveying techniques: Digital level, Total station, RTKGPS and extract linear measurements from orthophotos.

\section{THE SURVEY INSTRUMENTS}

The Global Positioning System (GPS) used was Leica viva GNSS receiver,

Figure (1, a, which measures the incoming phase of the satellite signals to high levels of precision in repeated measurements (Kostov, 2011). The Leica TS02, total station was used,

Figure (1, b. The total station is a digital theodolite integrated with an electronic distance measurement (EDM) to read slope distances from the instrument to a particular point and reduce it to horizontal by observing the vertical angle. The Leica DNA03 digital level was also used,

Figure (1, c, leveling with digital levels and barcode rods is the technique used to establish vertical control points. The accurate results were obtained when all systematic errors were controlled. Short sight lengths and balanced sights were the most limiting restrictions.

Figure (1) : a) Leica GPS receiver GS10 Base station and GS15 rover, b) Total station and c) Digital level DNA03 


\section{WORK PLAN}

1.Two areas were tested within the University of Duhok campus, area 1 was approximately flat and in the second area there were large variations in slopes. The natural point features were recognized well on orthophotos. The aim was to evaluate the accuracy and precision of the instrument survey used in this study to provide accurate horizontal and vertical position in such areas.

2. Several well identified points were distributed in two selected areas and their corresponding points appeared on orthophotos. For this reason an accurate reference height was created based on the first order vertical control point where the orthometric height was known with the aid of precise leveling procedure using Leica Digital level DNA03. The leveling procedure started from the first order point and closed to the control point (FP05). This point was established by Vossing German Company in Duhok region as illustrated in

Figure (2. The height of all selected points in the two tested areas were compared with the GPS and total station.

3.Several known control points were used as check points for evaluating the quality of measurements.

4. Extracted linear features from orthophotos of the two selected areas were used for evaluating the accuracy of orthophotos compared to the GPS and TS.
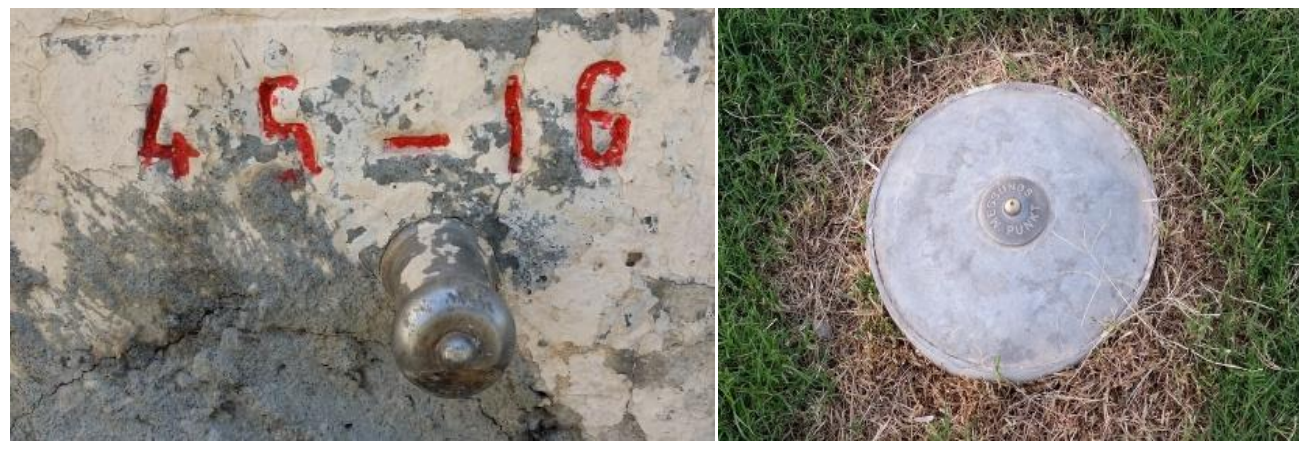

FP-05

\begin{tabular}{ll} 
& \multicolumn{1}{c}{ FP-05 } \\
FID & 4 \\
\hline ID & FP-05 \\
X & 315253.249 \\
Y & 4081333.339 \\
\hline Height & 540.999
\end{tabular}

Figure (2) : Left. First order vertical control point, right. FP05, Vossing, German control point in Duhok

\section{TEST AREA AND DATA COLLECTION}

The study area is located in two test sites around the university campus, university of Duhok. First, reconnaissance of the two selected areas of study were performed, and followed by fixing 34 and 10 control points as reference points for both selected areas respectively, which have been used as a reference value for a detailed survey. These points have been established using Leica TS02, GPS, and Digital level
DNA03 for measuring the height of all points of the selected areas.

Figure ( 3 shows the study area and the reference control points. The control point, $\mathrm{C} 12$ and C2 were previously surveyed by the university's survey team, 2011 using GPS in static mode with high accuracy and it was considered as a true GCPs.

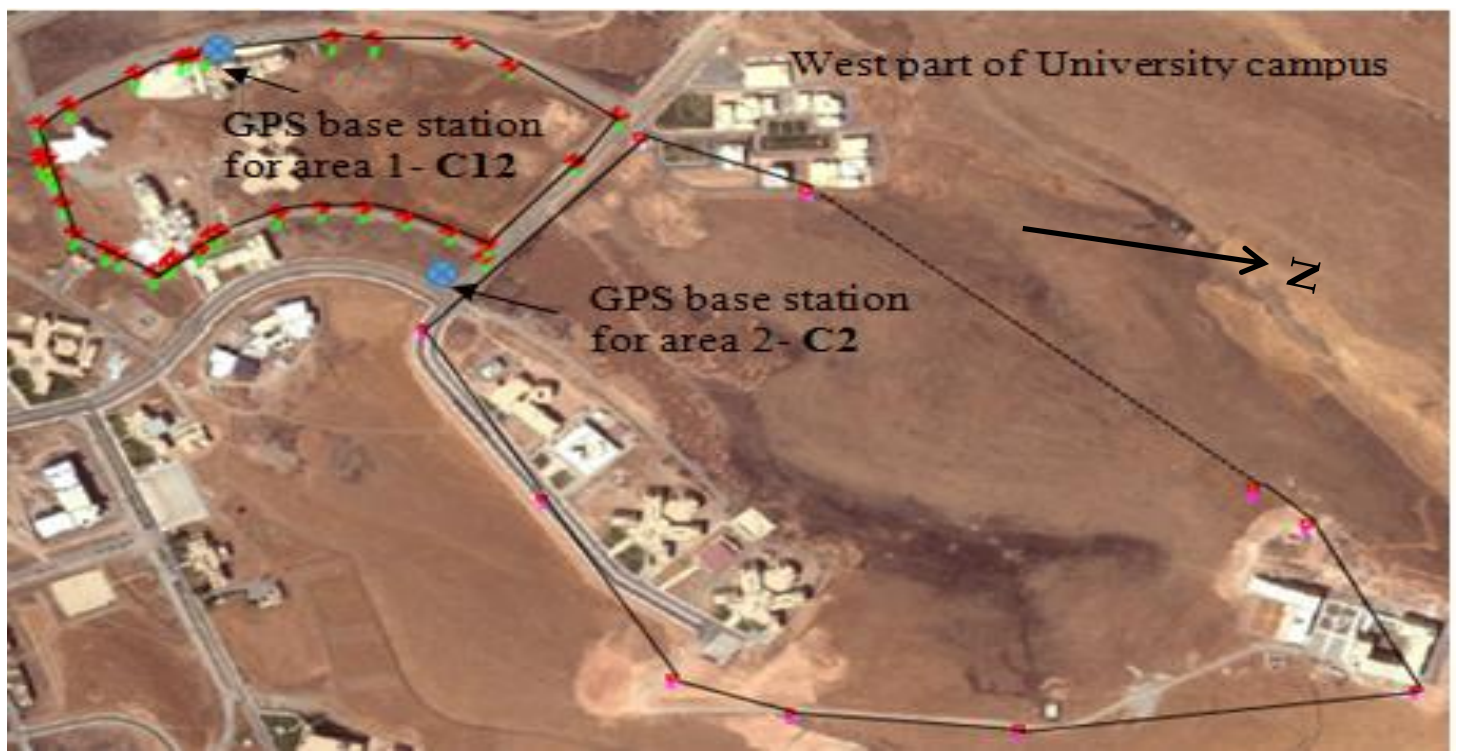

Figure (3) : The location of the control points in the two selected areas 


\section{A. Field Measurements of the Two test Areas}

Points in the first test site were distributed over an area of $300 \times 540 \mathrm{~m}$ and height range between $486 \mathrm{~m}$ and 504 $\mathrm{m}$. the selected points were well defined featured points e.g. road curb corner, building corners and road intersections. The survey loop works were carried out from control point $\mathrm{C} 12$ and closed to the starting point (C12). The points of the second area spread over $450 \times 700 \mathrm{~m}$ and the height range was between $504 \mathrm{~m}$ and $557 \mathrm{~m}$. The survey works start from the study area1 passing through the roads around the building which linked to the first study area as illustrated in
Figure (3. All of these points were measured on the GPS system, Total Station and precise Digital level. The Leica viva differential GPS was used in two test areas as mentioned before. In area 1, the Leica GS10, base station was set up on a highly accurate control point, C12, and its known coordinates can be shown in Figure $(4$, left. This control point (C12) was used as a base station to provide and establish reference points in the area of interest to be used for comparison using Leica GS15 in RTK mode as shown in Figure (4, right.

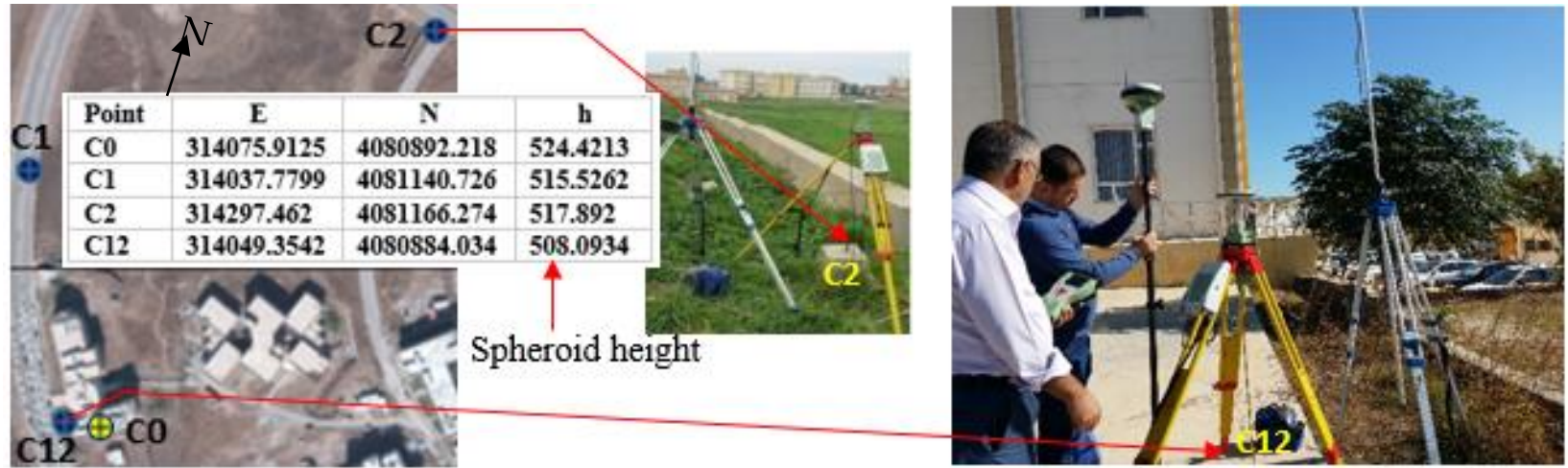

Figure (4) : left, Control pointsC0, C1, C2 and C12 with its known coordinate. Right: GPS-RTK set up on the Reference point $\mathrm{C} 2$ and $\mathrm{C} 12$.

The GNSS, GS15 receiver was used as a rover for measuring and recording data on the selected points for comparison with total station. The vertical component of these points was also measured. The coordinate system of the point was in WGS84. The spheroid height of all recorded points were converted to geodetic height by subtracting the average difference $=17.62 \mathrm{~m}$ which is the separation between spheroid and Geoid in the selected area of study. This value is not constant but varies depending on the local geoid in Iraq. This technique (GPS- RTK) was implemented to measure and record all the required points in two selected areas using the known coordinate points (C12) and (C2). The system measured the selected points five times to obtain the reported positional accuracy which was around 8 $\mathrm{mm}$. The height of all points in the study area were based on the first order control point where the orthometric height was known $(486.8159 \mathrm{~m})$. The levelling procedure started from the first order point ID (45-16) and closed to FP-05 control point,

Figure (2. This control point was used for validating the quality of geodetic height in the study area. Differential leveling was carried out on selected points on the two tested areas using Precise Digital level DNA03 with the precision of $0.2 \mathrm{~mm}$. A closed-loop leveling procedure was adopted. The measurement was repeated three times, and the average value was taken and stored automatically by the digital level device. The elevation errors obtained from the leveling process were within the allowable accuracy. Since the permissible closure for a level circuit is based upon the lengths of lines or the number of setups, it is logical to adjust the elevation on this basis to get the required precision.

\section{B. Results}

Table 1 shows the deviation in height value between GPS and reference (GPS elev. - DL elev.) Points in area1 have a maximum deviation in the range of $-4 \mathrm{~cm}$ to -8 $\mathrm{cm}$ and increase to $18 \mathrm{~cm}$ in point $\mathrm{F} 28$. While, the maximum deviation in height obtained via TS (TS elev.DL elev.) in the range of $\pm 1 \mathrm{~cm}$ to $\pm 4 \mathrm{~cm}$ and increase to $22 \mathrm{~cm}$ in point F28. The RMSE of both instruments GPS and TS are close around $\pm 0.038 \mathrm{~m}$. When the point F28 remove from the measurement, the RMSE improved to \pm 0.015 for TS and \pm 0.013 for GPS in height measurements. 


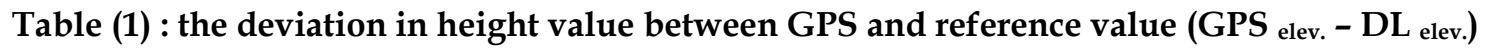

\begin{tabular}{|c|c|c|c|c|c|}
\hline Point & $\begin{array}{c}\text { Digital Level } \\
\text { elevation (DL elev.) }\end{array}$ & $\begin{array}{c}\text { GPS } \\
\text { Elevation }\end{array}$ & $\triangle \mathrm{GPS}, \mathrm{DL}$ & $\begin{array}{c}\text { TS } \\
\text { elevation }\end{array}$ & $\Delta \mathrm{TS}, \mathrm{DL}$ \\
\hline $\mathrm{C} 1$ & 515.5305 & 515.526 & -0.0045 & 515.5762 & 0.04565 \\
\hline $\mathrm{F} 1$ & 515.3244 & 515.3184 & -0.006 & 515.3484 & 0.024 \\
\hline $\mathrm{F} 2$ & 522.6382 & 522.6301 & -0.0081 & 522.6501 & 0.0119 \\
\hline F3 & 522.5609 & 522.5543 & -0.0066 & 522.5343 & -0.0266 \\
\hline F4 & 518.5549 & 518.5372 & -0.0177 & 518.5672 & 0.0123 \\
\hline F5 & 515.8727 & 515.8581 & -0.0146 & 515.8881 & 0.0154 \\
\hline $\mathrm{F} 6(\mathrm{c} 2)$ & 517.867 & 517.8681 & 0.0011 & 517.8981 & 0.0311 \\
\hline F7 & 513.8917 & 513.8799 & -0.0118 & 513.919 & 0.0273 \\
\hline F8 & 512.5346 & 512.523 & -0.0116 & 512.563 & 0.0284 \\
\hline F9 & 511.9193 & 511.896 & -0.0233 & 511.936 & 0.0167 \\
\hline F10 & 511.363 & 511.346 & -0.017 & 511.376 & 0.013 \\
\hline F11 & 509.7168 & 509.6933 & -0.0235 & 509.7333 & 0.0165 \\
\hline $\mathrm{F} 12$ & 509.3316 & 509.3024 & -0.0292 & 509.3424 & 0.0108 \\
\hline F13 & 508.5591 & 508.5233 & -0.0358 & 508.5633 & 0.0042 \\
\hline F14 & 507.1896 & 507.1553 & -0.0343 & 507.1953 & 0.0057 \\
\hline F15 & 506.7915 & 506.7595 & -0.032 & 506.7895 & -0.002 \\
\hline F16 & 505.8153 & 505.7806 & -0.0347 & 505.8206 & 0.0053 \\
\hline F17 & 504.3583 & 504.3127 & -0.0456 & 504.3527 & -0.0056 \\
\hline F18 & 503.9598 & 503.9175 & -0.0423 & 503.9475 & -0.0123 \\
\hline F19 & 502.9875 & 502.9463 & -0.0412 & 502.9763 & -0.0112 \\
\hline F20 & 502.1044 & 502.0659 & -0.0385 & 502.0959 & -0.0085 \\
\hline F21 & 501.585 & 501.5477 & -0.0373 & 501.5777 & -0.0073 \\
\hline $\mathrm{F} 22$ & 501.238 & 501.2048 & -0.0332 & 501.2448 & 0.0068 \\
\hline F23 & 501.1673 & 501.1398 & -0.0275 & 501.1698 & 0.0025 \\
\hline F24 & 501.1473 & 501.0993 & -0.048 & 501.1293 & -0.018 \\
\hline F25 & 501.2249 & 501.1893 & -0.0356 & 501.2193 & -0.0056 \\
\hline F26 & 503.371 & 503.3375 & -0.0335 & 503.3675 & -0.0035 \\
\hline $\mathrm{F} 27$ & 504.7158 & 504.6833 & -0.0325 & 504.7233 & 0.0075 \\
\hline F28 & 505.9011 & 506.0835 & 0.1824 & 506.1235 & 0.2224 \\
\hline
\end{tabular}




\begin{tabular}{|c|c|c|c|c|c|}
\hline F29 & 506.1254 & 506.0825 & -0.0429 & 506.1225 & -0.0029 \\
\hline F30 & 507.3777 & 507.3415 & -0.0362 & 507.3815 & 0.0038 \\
\hline F31 & 507.6004 & 507.554 & -0.0464 & 507.594 & -0.0064 \\
\hline F32(c12) & 508.0989 & 508.072 & -0.0269 & 508.112 & 0.0131 \\
\hline F33 & 512.6362 & 512.6145 & -0.0217 & 512.6545 & 0.0183 \\
\hline F34 & 514.0425 & 514.0097 & -0.0328 & 514.0397 & -0.0028 \\
\hline & & RMSE & $\mathbf{0 . 0 3 7 9}$ & & $\mathbf{0 . 0 3 9 5}$ \\
\hline
\end{tabular}

The height deviation of GPS and TS in Area2 compared to reference height (Digital level) as shown in Figure (5 has less accuracy than area 1 . This can be explained by

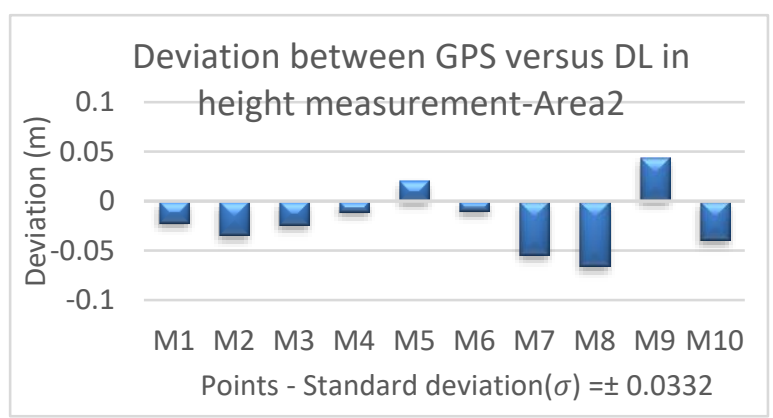

large variations in slope and the wide length between selected points.

Figure (5) : Deviation in height measurements, university site area2. Left: GPS versus Reference height (DL). Right: TS versus Reference height.

\section{THE QUALITY OF GPS IN THE AREA OF STUDY}

In the previous section, 4 a, the GPS- RTK technique was implemented to compare the accuracy of all points in two selected areas. RTK was used to measure the selected points five times to get better 3D quality, reported by the receiver, which less than $8 \mathrm{~mm}$. This 3D quality refers to the accuracy of the GPS measurement in relation to the base station. The value of the $3 \mathrm{D}$ quality can be small or large depending on the satellite availability and other sources of errors that affect the GPS measurement. The Equation 1 below express the 3D quality $\left(\sigma_{e n h}\right)$.

$\sigma_{e n h}=\sqrt{\sigma_{e}^{2}+\sigma_{n}^{2}+\sigma_{h}^{2}}$

Where:

$\sigma$ is the standard deviation of $\mathrm{E}, \mathrm{N}$ and $\mathrm{h}$ coordinates

RTK measurements were taken to compare with the total station measurements; all selected points were surveyed five times so as to evaluate the precision of the measurements. In order to evaluate how much the measurements were close to the established value, the standard deviation and RMS of the RTK measurements were computed using Equation 1.

The results showed that the standard deviations were less than $8 \mathrm{~mm}$ in the horizontal coordinate and they reached $16 \mathrm{~mm}$ in the vertical coordinate as shown in figure 6, left, which indicated that the repeated measurements were close to each other. These results were better than the results that were obtained by Jonsson K.O. et al. (2003), the standard deviations for the horizontal and vertical coordinate were $9 \mathrm{~mm}$ and $20 \mathrm{~mm}$ respectively. While the results of RMS errors of RTK measurements, which indicated the accuracy of the RTK measurements of the reference network (see figure 6 , right), showed that the accuracy of the horizontal coordinates were about a maximum of $12 \mathrm{~mm}$ (points $\mathrm{F} 15,20,21,25,27$ and 34) and minimum of $5 \mathrm{~mm}$ (point F22). The point F14 was the only point that reached 15 $\mathrm{mm}$. The accuracy of the vertical coordinates ranged between a maximum of $23 \mathrm{~mm}$ (point F29) and a minimum of $12 \mathrm{~mm}$ (point F11). These errors were attributed to the obstruction of satellite visibility to the GPS receiver. By comparing the results of the accuracy of the horizontal coordinates with the work conducted by Ehsani et al. (2004), their results were about $10 \mathrm{~mm}$ achieved, which were close to each other. This closeness of the results can be explained by compensating for atmospheric delay, orbital errors and other variables in GPS geometry. 

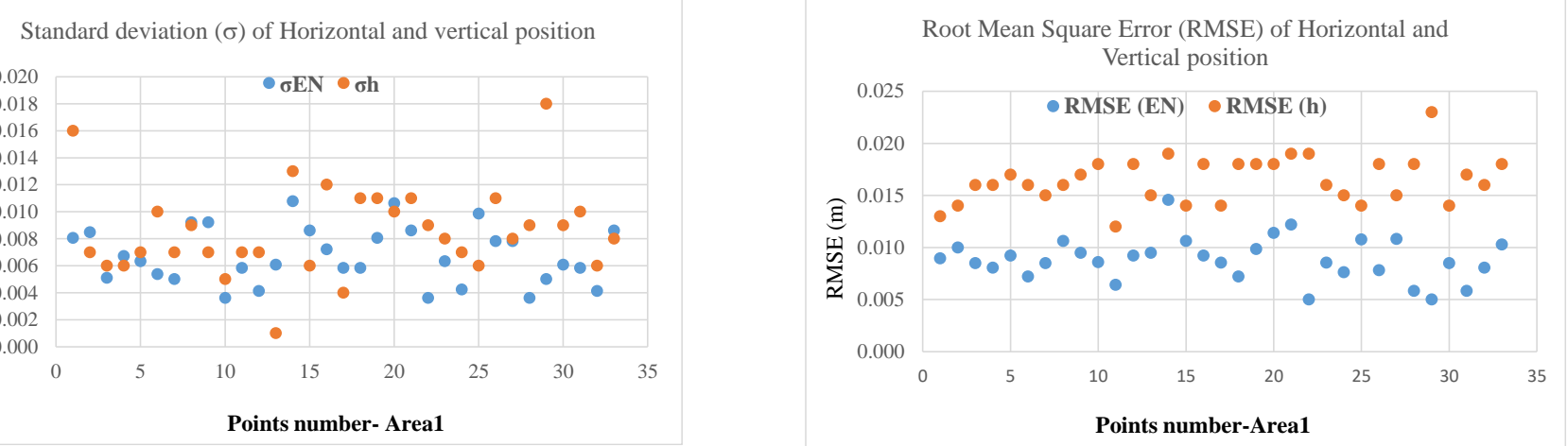

Figure (6) : GPS- RTK measurements: Left. Standard deviations. Right. RMSE -Area1

The accuracy of RMSE and standard deviation of each measurement in area 2 is listed in Table $(2$ and the results were better than area1. This is attributed to the visibility of GPS signals to satellites which were better than area 1 (see figure 3 ).

Table (2) : GPS-RTK measurement, its RMSE and standard deviations -Area2.

\begin{tabular}{|c|c|c|c|c|c|c|c|c|c|}
\hline \multirow{2}{*}{ Point } & Easting & Northing & Height & E & $\mathrm{N}$ & $\mathrm{H}$ & $\sigma \mathrm{E}$ & $\sigma \mathrm{N}$ & $\sigma \mathrm{H}$ \\
\hline & \multicolumn{3}{|c|}{ Mean value of RTK } & \multicolumn{3}{|c|}{ RMSE } & \multicolumn{3}{|c|}{ Standard deviation $(\sigma)$} \\
\hline M1 & 314160.044 & 4081318.212 & 523.308 & 0.007 & 0.008 & 0.017 & 0.007 & 0.006 & 0.008 \\
\hline M2 & 314226.572 & 4081485.767 & 534.150 & 0.007 & 0.008 & 0.012 & 0.005 & 0.008 & 0.015 \\
\hline M3 & 314406.865 & 4081101.408 & 521.907 & 0.005 & 0.007 & 0.013 & 0.005 & 0.005 & 0.003 \\
\hline M4 & 314628.448 & 4081221.141 & 530.138 & 0.005 & 0.006 & 0.012 & 0.003 & 0.003 & 0.006 \\
\hline M5 & 314862.189 & 4081350.542 & 550.638 & 0.008 & 0.007 & 0.013 & 0.007 & 0.002 & 0.004 \\
\hline M6 & 314909.087 & 4081468.695 & 562.926 & 0.008 & 0.007 & 0.022 & 0.002 & 0.003 & 0.001 \\
\hline M7 & 314930.097 & 4081697.052 & 583.653 & 0.003 & 0.006 & 0.015 & 0.001 & 0.001 & 0.002 \\
\hline M8 & 314877.199 & 4082093.428 & 606.289 & 0.007 & 0.008 & 0.017 & 0.007 & 0.006 & 0.008 \\
\hline M9 & 314663.408 & 4081985.125 & 594.615 & 0.003 & 0.004 & 0.12 & 0.001 & 0.003 & 0.006 \\
\hline \multirow[t]{3}{*}{ M10 } & 314616.142 & 4081931.075 & 587.641 & 0.004 & 0.006 & 0.015 & 0.003 & 0.001 & 0.004 \\
\hline & & & & \pm 0.002 & \pm 0.00 & \pm 0.03 & \pm 0.002 & \pm 0.002 & \pm 0.004 \\
\hline & & & & \multicolumn{3}{|c|}{ RMSE $(\mathrm{enh})= \pm 3 \mathrm{~mm}$} & \multicolumn{3}{|c|}{$\sigma(e n h)= \pm 4.9 \mathrm{~mm}$} \\
\hline
\end{tabular}

A. Measurements of TS and GPS versus Check points The RMSE and standard deviation for the position (ENh) were also calculated between the RTK mode and Total station coordinates versus check points in the two study areas and the results are shown in Table 3 using the Equation 2.

$R M S E($ enh $)=\sqrt{\frac{\sum_{i=1}^{5}(A-B)^{2}}{n}} ; \quad R M S E(e n h)=\sqrt{\frac{\sum_{i=1}^{5}(A-C)^{2}}{n}}$

Table (3) : RMSE and standard deviation of the position for each measurement versus check points

\begin{tabular}{|c|c|c|c|}
\hline \multirow{2}{*}{$\begin{array}{l}\text { Test } \\
\text { area }\end{array}$} & \multirow{2}{*}{$\begin{array}{l}\text { Check points } \\
\text { position enh } \\
\text { (m) (A) }\end{array}$} & \multicolumn{2}{|c|}{ Position enh $(\mathrm{m})$} \\
\hline & & $\begin{array}{c}\text { enh }(\mathrm{m}), \mathrm{TS} 02 \\
(\mathrm{~B})\end{array}$ & $\begin{array}{l}\text { enh (m), RTK- } \\
\text { GPS (C) }\end{array}$ \\
\hline \multicolumn{4}{|c|}{ Area1:RMSE $(e n h)=\sqrt{\frac{\sum_{i=1}^{5}(A-B)^{2}}{n}}$} \\
\hline RMSE & & 0.124 & 0.435 \\
\hline бenh & & 0.222 & 0.345 \\
\hline
\end{tabular}




\begin{tabular}{|c|c|c|}
\hline Are & $\sqrt{\frac{\sum_{i=1}^{5}(A-B)^{2}}{n}}$; & $\operatorname{RMSE}($ enh $)=$ \\
\hline RMS & 0.233 & 0.322 \\
\hline$\sigma e n h$ & 0.244 & 0.127 \\
\hline
\end{tabular}

\section{B. Accuracy Analysis}

To verify the quality of measurements, the mean value of 10 measurements of the TS and RTK measurements were compared and the results showed that the compatibility between the two measurements were accurate and precise. Table ( 4 shows that the maximum deviation in the horizontal and vertical position of both areas between TS and RTK were $5 \mathrm{~mm}$ and $11 \mathrm{~mm}$ respectively.

Table (4): The difference between TS and RTK mean in two selected areas

\begin{tabular}{|c|c|c|c|c|c|c|c|c|c|}
\hline \multirow{2}{*}{$\begin{array}{r}\text { Point/ } \\
\text { area1 }\end{array}$} & \multicolumn{4}{|c|}{ TS mean- RTK mean } & \multirow{2}{*}{$\begin{array}{r}\text { Point/ } \\
\text { area2 }\end{array}$} & \multicolumn{4}{|c|}{ TS mean-RTKmean } \\
\hline & $\Delta \mathrm{E}$ & $\Delta \mathbf{N}$ & $\Delta \mathrm{EN}$ & $\Delta \mathbf{H}$ & & $\Delta \mathrm{E}$ & $\Delta \mathbf{N}$ & $\Delta \mathrm{EN}$ & $\Delta \mathbf{H}$ \\
\hline F2 & -0.002 & -0.003 & 0.004 & 0.006 & M1 & -0.003 & 0.004 & 0.005 & 0.011 \\
\hline F3 & 0.001 & -0.004 & 0.004 & 0.007 & M2 & 0.004 & -0.003 & 0.001 & 0.010 \\
\hline F5 & -0.003 & 0.002 & 0.004 & 0.005 & M3 & -0.001 & -0.001 & 0.002 & -0.008 \\
\hline F7 & -0.001 & 0.002 & 0.002 & -0.008 & M4 & 0.001 & 0.002 & 0.001 & 0.006 \\
\hline F10 & 0.004 & -0.003 & 0.005 & 0.011 & M5 & -0.001 & -0.001 & 0.003 & 0.005 \\
\hline F12 & -0.002 & 0.004 & 0.004 & 0.007 & M6 & -0.002 & 0.002 & 0.003 & 0.004 \\
\hline F17 & 0.003 & -0.001 & 0.003 & 0.009 & M7 & 0.001 & 0.003 & 0.005 & 0.003 \\
\hline F22 & 0.004 & 0.003 & 0.005 & 0.006 & M8 & -0.003 & -0.004 & 0.004 & -0.011 \\
\hline F24 & -0.002 & -0.003 & 0.004 & 0.004 & M9 & 0.002 & -0.003 & 0.001 & 0.009 \\
\hline F26 & -0.004 & -0.003 & 0.005 & 0.008 & M10 & -0.001 & 0.001 & 0.005 & 0.005 \\
\hline
\end{tabular}

The standard deviation of the difference between total station and RTK of the ten measurements were also calculated using Equation 3 and 4. The results showed that the maximum difference in standard deviation of horizontal position was $\pm 9 \mathrm{~mm}$ and $\pm 17 \mathrm{~mm}$ in vertical position as shown in

$\sigma_{d(G P S, R T K-T S) i}=\sqrt{\sigma_{T S i}^{2}+\sigma_{G P S, R T K i}^{2}}$

(4)

Where; $d_{(G P S, R T K-T S) i}$ is the difference between TS and GPS, RTK coordinates, $\sigma_{d(G P S, R T K-T S) i}$ is the standard deviation of $d_{(G P S, R T K-T S) i}$.

Figure (7.

$d_{(G P S, R T K-T S) i}=\operatorname{Corrd}_{\cdot T S i}-\operatorname{Coord}_{\cdot G P S, R T K i}$

(3)

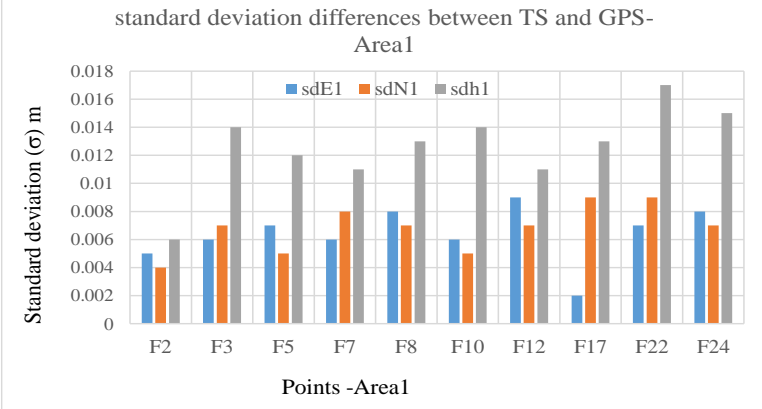

Standard deviation differences between TS and GPS- Area2

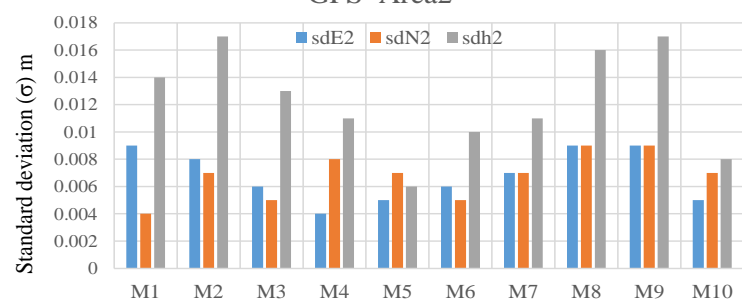

Figure (7) : Standard deviation differences between TS and GPS in two selected areas. Left: Area 1. Right: Area2

Figure (7 shows that the maximum standard deviation of the differences between total station and RTK in the two selected areas for horizontal and vertical components, where in area1 $11 \mathrm{~mm}$ in point (F12) and 17 $\mathrm{mm}$ in point (F22) were detected respectively. In area 2, the points detected were $12 \mathrm{~mm}$ in point (M8 and M9) and $17 \mathrm{~mm}$ in points (M2 and M9). The maximum 3D deviation between TS position and RTK position in both areas were $22 \mathrm{~mm}$. While the minimum 3D deviation of the differences between TS position and RTK position in both areas were around $7 \mathrm{~mm}$ in area1 and $8 \mathrm{~mm}$ in area2. The average standard deviation $(\sigma h)$ differences in vertical position and the total of $3 \mathrm{D}$ deviation 
(Toenh) in the two selected areas were close to each other. This means that there were no significant

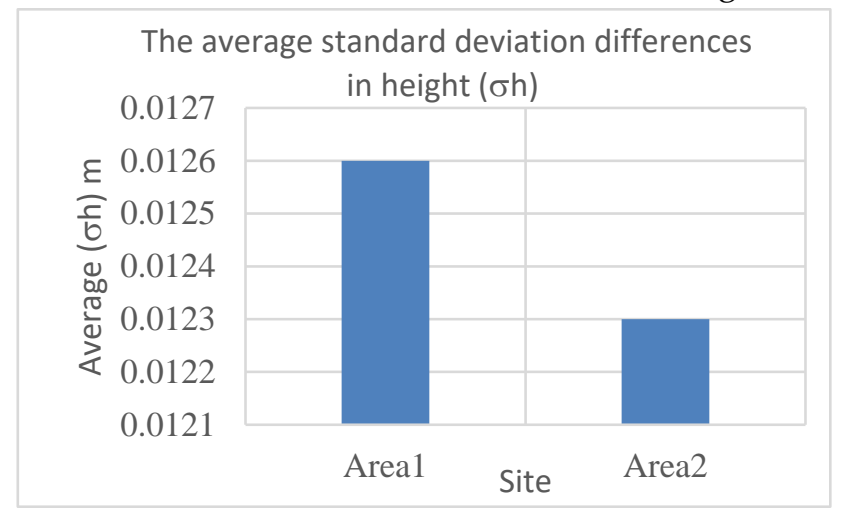

differences in measurements as shown in Figure $(8$.

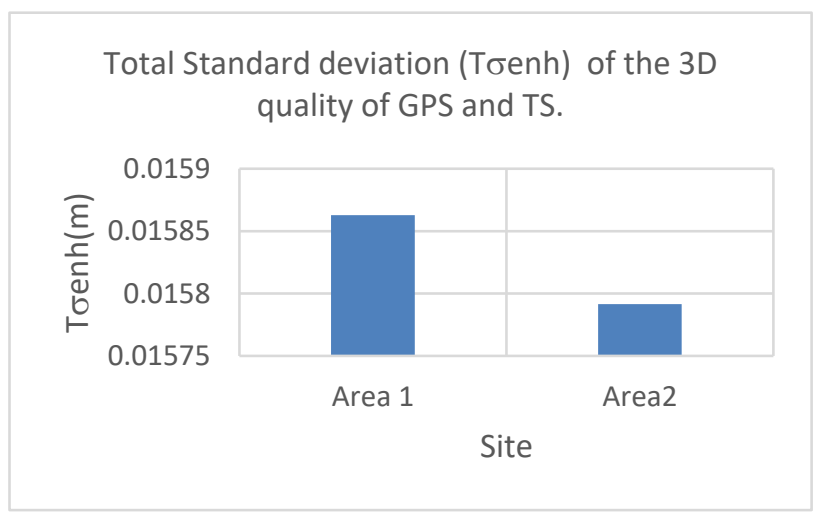

Figure (8) : Left: The average differences of standard deviation of vertical position, and Right: The total standard deviation of the differences in position between GPS and TS in two area of study.

\section{LINEAR ACCURACY}

Linear accuracy was assessed between surveys instruments used in this paper relative to the actual length. The actual length was measured with steel tape up to millimeter accuracy and considered to be a base for comparison. A test was carried out in regular buildings for the two selected areas of study as illustrated in Figure (9. The results were compared between measured lengths in relation to the base (steel tape) as can be shown in Table 5. The distances of each line as shown in Figure $(\mathbf{9}$ were computed using coordinates of each point measured by GPS and TS. While the length of those lines were measured directly using AutoCAD civil 3D software.
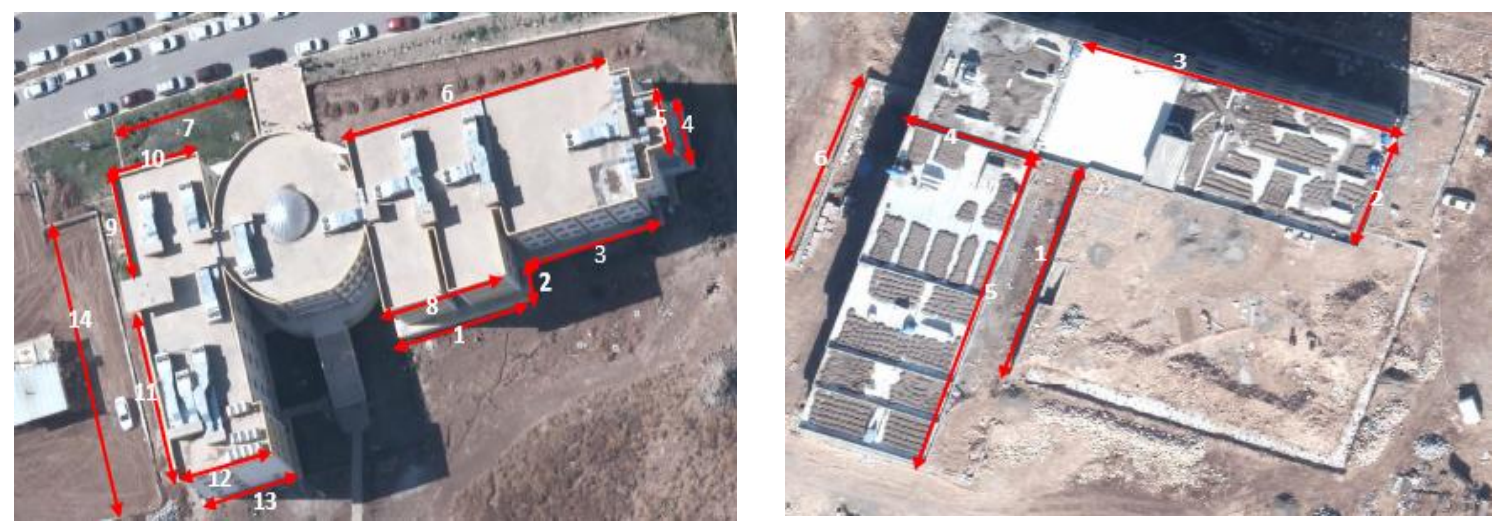

Figure (9) : Measured length of regular building highlighted in Orthophoto of the Vossing German Company. Left, area 1. Right, area 2

Table (5) : Linear accuracy of sensor recorded length-Area1

\begin{tabular}{|c|c|c|c|c|c|c|c|}
\hline \multirow{2}{*}{$\begin{array}{c}\text { Regular } \\
\text { Building } \\
\text { Area1 }\end{array}$} & \multirow{2}{*}{$\begin{array}{l}\text { Steel tape side } \\
\text { length }(\mathrm{m}),(\mathrm{A})\end{array}$} & \multicolumn{3}{|c|}{ Side lengths (m) } & \multicolumn{3}{|c|}{ Differences (m) } \\
\hline & & TS02 (B) & $\begin{array}{c}\text { DGPS } \\
\text { (C) }\end{array}$ & $\begin{array}{l}\text { Orthophoto } \\
\text { (D) }\end{array}$ & A-B & A-C & A-D \\
\hline 1 & 21.500 & 21.480 & 22.250 & 21.44441 & 0.02 & -0.75 & 0.05559 \\
\hline 2 & 4.900 & 4.880 & 5.240 & 5.10905 & 0.02 & -0.34 & -0.2090 \\
\hline 3 & 22.210 & 22.220 & 22.580 & 22.31728 & -0.01 & -0.37 & -0.1073 \\
\hline 4 & 9.870 & 9.820 & 9.880 & 9.81736 & 0.05 & -0.01 & 0.05264 \\
\hline 5 & 7.530 & 7.66 & 7.640 & 7.75665 & -0.13 & -0.11 & -0.2266 \\
\hline 6 & 42.070 & 41.950 & 41.080 & 42.23595 & 0.12 & 0.99 & -0.1659 \\
\hline 7 & 21.400 & 21.409 & 21.370 & 21.43246 & -0.009 & 0.03 & -0.0324 \\
\hline 8 & 19.610 & 19.640 & 19.630 & 19.66377 & -0.03 & -0.02 & -0.0538 \\
\hline
\end{tabular}




\begin{tabular}{cccccccc}
\hline 9 & 15.500 & 15.804 & 15.520 & $\mathbf{1 4 . 4 0 7 0 5}$ & -0.304 & -0.02 & 1.09295 \\
\hline 10 & 13.850 & 13.841 & 13.820 & 13.90942 & 0.009 & 0.03 & -0.0594 \\
\hline 11 & 24.250 & 24.245 & 24.270 & 24.21164 & 0.005 & -0.02 & 0.03836 \\
\hline 12 & 15.000 & 15.060 & 15.120 & 15.15949 & -0.06 & -0.12 & -0.1595 \\
\hline 13 & 15.200 & 15.180 & 15.450 & 15.16462 & 0.02 & -0.25 & 0.03538 \\
\hline 14 & 41.120 & 41.114 & 41.100 & 41.13 & 0.006 & 0.02 & -0.01 \\
\hline 15 & 13.065 & 13.075 & 13.076 & 13.078 & -0.01 & -0.011 & -0.013 \\
\hline & \multicolumn{2}{r}{ Standard deviation $\mathbf{( \sigma )}$} & & & $\mathbf{0 . 0 9 5}$ & $\mathbf{0 . 3 6 1}$ & $\mathbf{0 . 3 1 2}$ \\
\hline
\end{tabular}
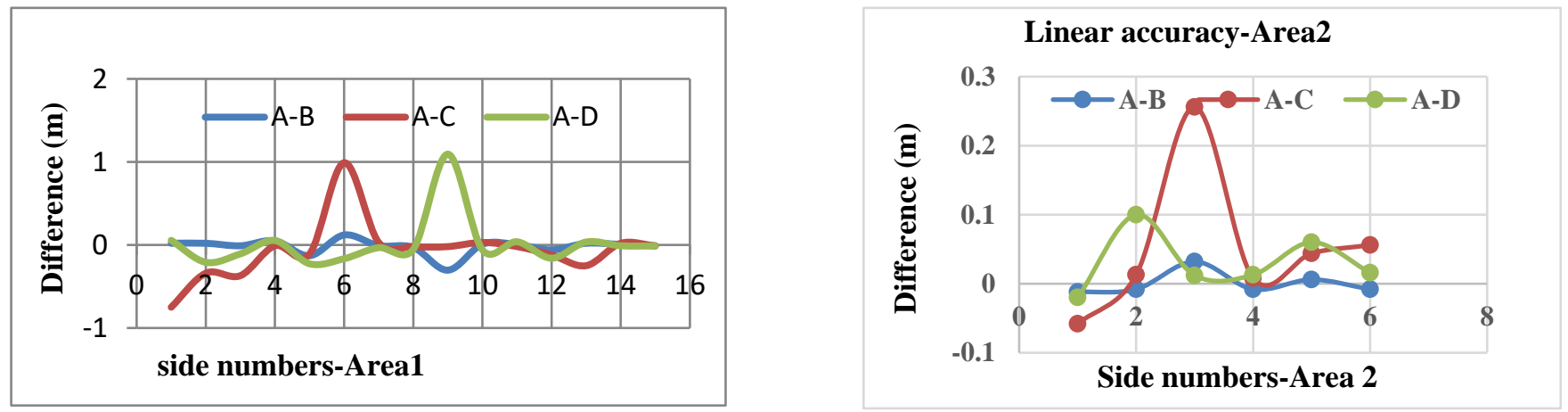

Linear accuracv -Area1

Figure (10) : the deviation in length between sensors relative to the actual length: left. Area1. Right.Area2

As shown in Figure (10, the high discrepancy in GPS and orthophoto for measured length relative to fixed length (length measured by steel tape) was clearly $1 \mathrm{~m}$ in area 1 which was a higher value relative to those measured in area2. The discrepancy in TS for measuring length in both areas relative to the fixed length was more accurate than GPS and orthophotos. This is because the GPS is not accurate when close to the building due to the obstruction of the GPS signal in satellite visibility. While the errors of the aerial photos' resulted from relief displacement in height variations of the selected area of study.

\section{CONCLUSIONS}

The purpose of this project work was to evaluate and compare accuracy and precision of surveying techniques (Digital level, TS, GPS and data from orthophotos). The comparison was carried out between Digital level versus TS and GPS-RTK on the reference network; and the accuracy of othophotos encountered to TS and GPS in measuring length on regular features such as buildings and other well defined features. To accomplish the objectives of the paper, three main tasks were implemented. Firstly: a network of 34 and 10 control points were established in two areas respectively with high precision $(0.2 \mathrm{~mm})$ with Digital level according to the instrument specification, and served as a reference value. Secondly: on the same network, total station and RTK methods were performed to compare the result with that of the digital level. Finally, the linear accuracy of orthophotos of
Vossing German company were evaluated in comparison with the survey instrument (GPS and TS) used in this study. It is possible to collect the 3D data of the object rapidly and in detail by the survey instruments mentioned in this research. However, the important steps is to decide the type of sensor to be applied. If there are close range photogrammetry, for instance Terrestrial Laser scanner or a none-metric camera is used instead of orthophotos, they will produce better results. As seen in this study, the measurement differences between the two selected areas are inversely proportional to the accuracy of the sensors used and directly proportional to instrument distance to the objects.

\section{REFERENCES}

1. ABDULRAHMAN, F. H. 2013. The use of targets to improve the precision of Mobile Laser Scanning.. PhD., thesis, University of Nottingham.

2. AHMED, E. M. 2012. Performance Analysis of the RTK Technique in an Urban Environment. Australian Surveyor, 45, 47-54.

3. AMIN, M. N. K. A. Z. M. Multipath Error Detection Using Different GPS Receiver's Antenna.. Proceedings of the 3rd FIG Regional Conference., October 3-7, 2004. 2004 Jakarta, Indonesia..

4. BORGELT S C., HARRISON J D., HARRISON, K. A. S. \& BIRRELL., S. J. 1996. Evaluation of GPS for Applications in Precision Agriculture. Appl. Eng. Agric., 12, 633-638.

5. CHEKOLE., S. D. 2014. Surveying with GPS, total 
station and terrestrial laser scanner: a comparative study.. Master of Science thesis in Geodesy Royal Institute of Technology (KTH), Stockholm, Sweden.

6. EHSANI, M. R., UPADHYAYA, S. K. \& MATTSON, M. L. 2004. Seed Location Mapping Using RTK GPS. Trans. ASAE., 47, 909-914.

7. JONSSON K.O., ANDERSSON A., JACOBSSON S.O., VANDEVOORDE S., LAMBERT D.M. \& C.J., F. 2003. SWEPOS Network-RTK Services, status, applications and experiences.. ION GPS/GNSS Portland, Oregon, U.S.A.
8. KOSTOV, G. P. 2011. Using of both Fast Static and RTK Modes for GNSS Determinations to Obtain Required high Accuracy and Productivity, According to the Current Possibilities of the IT.. Marrakech, Morocco. 9. LIN, L. S. Application of GPS RTK and total station systems on dynamic monitoring land use.. Proceedings of the ISPRS Congress., 2004 Istanbul, Turkey 10.SJÖBERG, L. E. 2012. Lecture notes on the course AH2923 Global Navigation Satellite System (GNSS), Division of Geodesy, KTH, Stockholm, Sweden. 